\title{
Two cases with different deletions of the long arm of chromosome 7
}

\author{
J. M. KLEP-DE PATER, J. B. BIJLSMA, E. M. BLEEKER-WAGEMAKERS, \\ H. F. DE FRANCE, AND C. M. A. M. DE VRIES-EKKERS
}

From the Observation Clinic 'De Ederhorst', Horalaan 5, Ede; and the Department of Human Genetics, University of Amsterdam, Amsterdam, The Netherlands

SUMmARY Two mentally and physically retarded girls, one with an interstitial deletion 7 (pter $\rightarrow$ q21 ::q32 $\rightarrow$ qter), and the other with an interstitial deletion 7 (pter $\rightarrow$ q11::q22 $\rightarrow$ qter), are described. Their clinical features are compared with those of 11 earlier reported cases with a deletion 7q. The Hageman factor, the locus of which is assigned to the distal part of 7q, was in both cases within normal limits. The data available do not justify the delineation of a specific clinical syndrome.

Deletions of a part of the long arm of chromosome 7 have been reported by De Grouchy et al. (1968), Shokeir et al. (1973), De Grouchy and Turleau (1974), Ayraud et al. (1976), Higginson et al. (1976), Harris et al. (1977), Kousseff et al. (1977), Valentine and Sergovich (1977), and Biederman and Bowen (1978). In the cases of Shokeir et al. (1973), De Grouchy and Turleau (1974), Harris et al. (1977), and Kousseff et al. (1977), the terminal part (q32 $\rightarrow$ qter) was missing; the case of Valentine and Sergovich (1977) was cytogenetically characterised by an interstitial deletion $7 \mathrm{q} 11 \rightarrow \mathrm{q} 22$. Ayraud et al. (1976) described a case with probable loss of segment 7q2. Biederman and Bowen (1978) showed a patient with a deletion of the long arm of chromosome 7, which is most likely an interstitial deletion. Received for publication 10 July 1978.
We report two girls with multiple congenital malformations as a result of interstitial deletion of the long arm of chromosome 7.

\section{Case reports}

CASE 1 (FIG. 1A)

This case was the third daughter of a gravida 3, para 3 woman, and was born on 21.2.72 in the vertex position. Pregnancy was marked by minimal weight gain and minimal fetal movement. The delivery was normal at term. Birthweight was $1500 \mathrm{~g}$ ( $<3$ rd centile), length $43.5 \mathrm{~cm}(<3$ rd centile), and head circumference $33 \mathrm{~cm}$ ( $<3$ rd centile). No other physical abnormalities were seen at that time. Because of an underdeveloped sucking reflex, feeding difficulties arose soon after birth. The initial
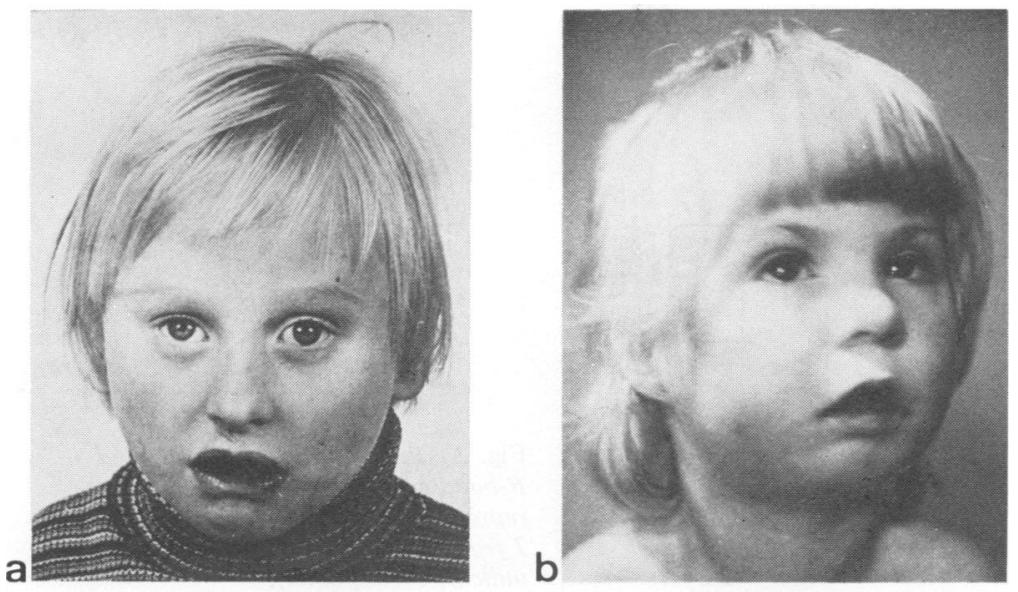

Fig. 1 (a) Case 1 at age 6: (b) case 2 at age 4. 
failure to thrive improved after spoon-feeding was introduced. Infancy and early childhood were complicated by recurrent respiratory and urinary tract infections. Clinical examination at the age of 6 showed a girl, small for her age, height $103.5 \mathrm{~cm}$ ( $<3$ rd centile), relatively obese, weight $16 \mathrm{~kg}$ (3rd centile), with a head circumference of $49 \mathrm{~cm}$ ( 25 th centile). The patient had brachycephaly, frontal bossing, sunken eyes, short philtrum, large mouth, large ears with prominent antihelices, widely spaced nipples, diastasis recti, a sacral dimple, and strongly curved large toenails. Neurological examination showed distinct hypotonia combined with hypertonia of the lower limbs. Electroencephalogram showed a diffuse abnormal pattern. There was severe psychomotor retardation, and the patient could not speak. Bone age was 5 years, 8 months. Routine laboratory investigations showed values within normal limits. Dermatoglyphic analysis showed bilateral simian creases, distally displaced axial triradii, and hypothenar patterns.
CASE 2 (FIG. 1 B)

This case was the daughter of a gravida 1 , para woman, born on 9.5.74. The mother was 28 year. old and the father 30 . The pregnancy was uneventfuff and ended at term in a normal delivery. Birthweight was $2160 \mathrm{~g}$ ( $<3$ rd centile), length $45 \mathrm{~cm}$ ( 3 rd centile) At birth only a cleft palate was noticed. Aftep surgical closure of the palatal defect at the age of $10^{\circ}$ feeding difficulties in infancy persisted. Initiat growth retardation improved after surgical correction of a diaphragmatic hernia when the patient was 2 years, 9 months old. There was no history ot, respiratory or urinary tract infections. Clinicas? examination at the age of 4 showed a mentally an $\overline{8}$ physically retarded girl, height $89 \mathrm{~cm}(<3$ rd centile), weight $9 \cdot 8 \mathrm{~kg}$ ( $<3$ rd centile for length), and hea circumference $44.5 \mathrm{~cm}(<3 \mathrm{rd}$ centile). She had brachycephaly, prominent forehead with low frontas? hairline, thick eyebrows (especially on the mediad side), slight epicanthus, strabismus convergens, broad nose bridge, small (non-bulbous) noses

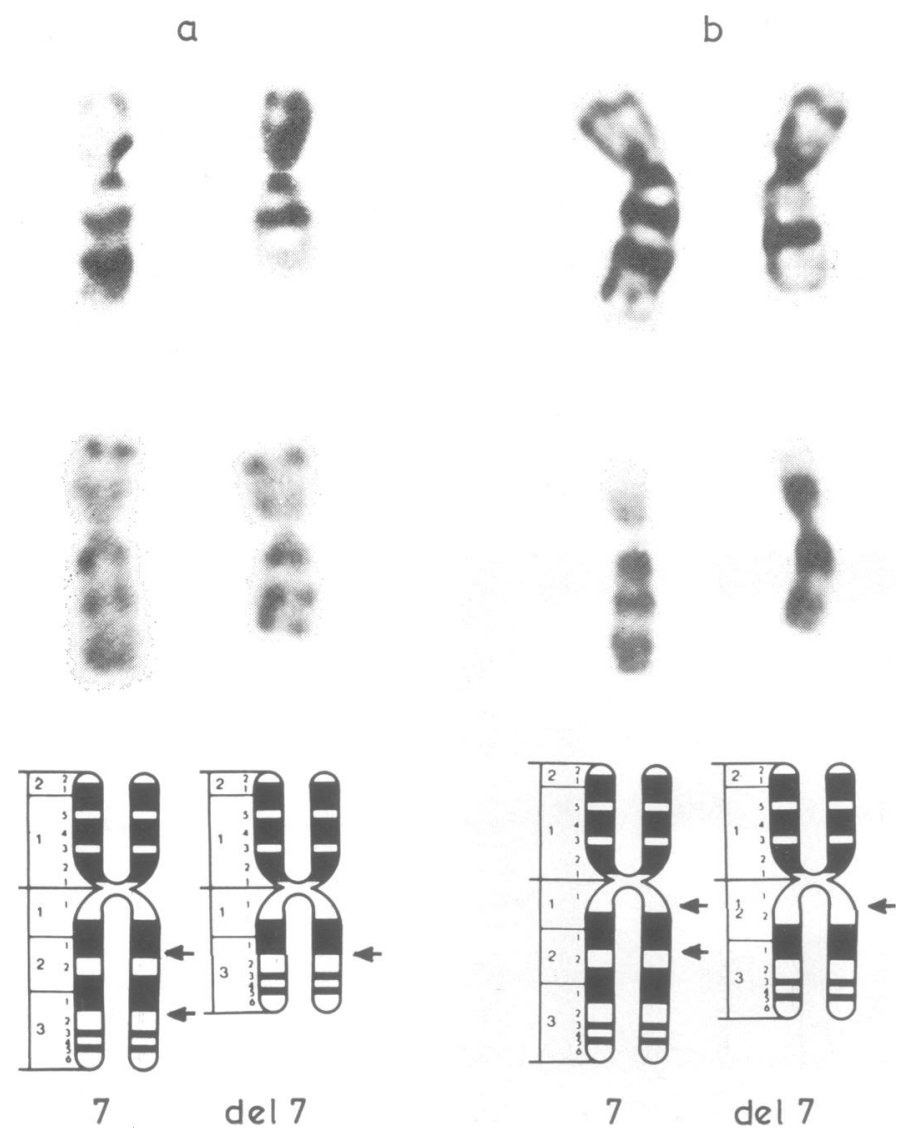

Fig. 2 Partial karyotypes (G- and $R$-banding pattern) and schematic representation of the deleted chromosome 7 from (a) case 1 and (b) case 2 (arrows $\mathbb{D}$ indicate breakpoints). 

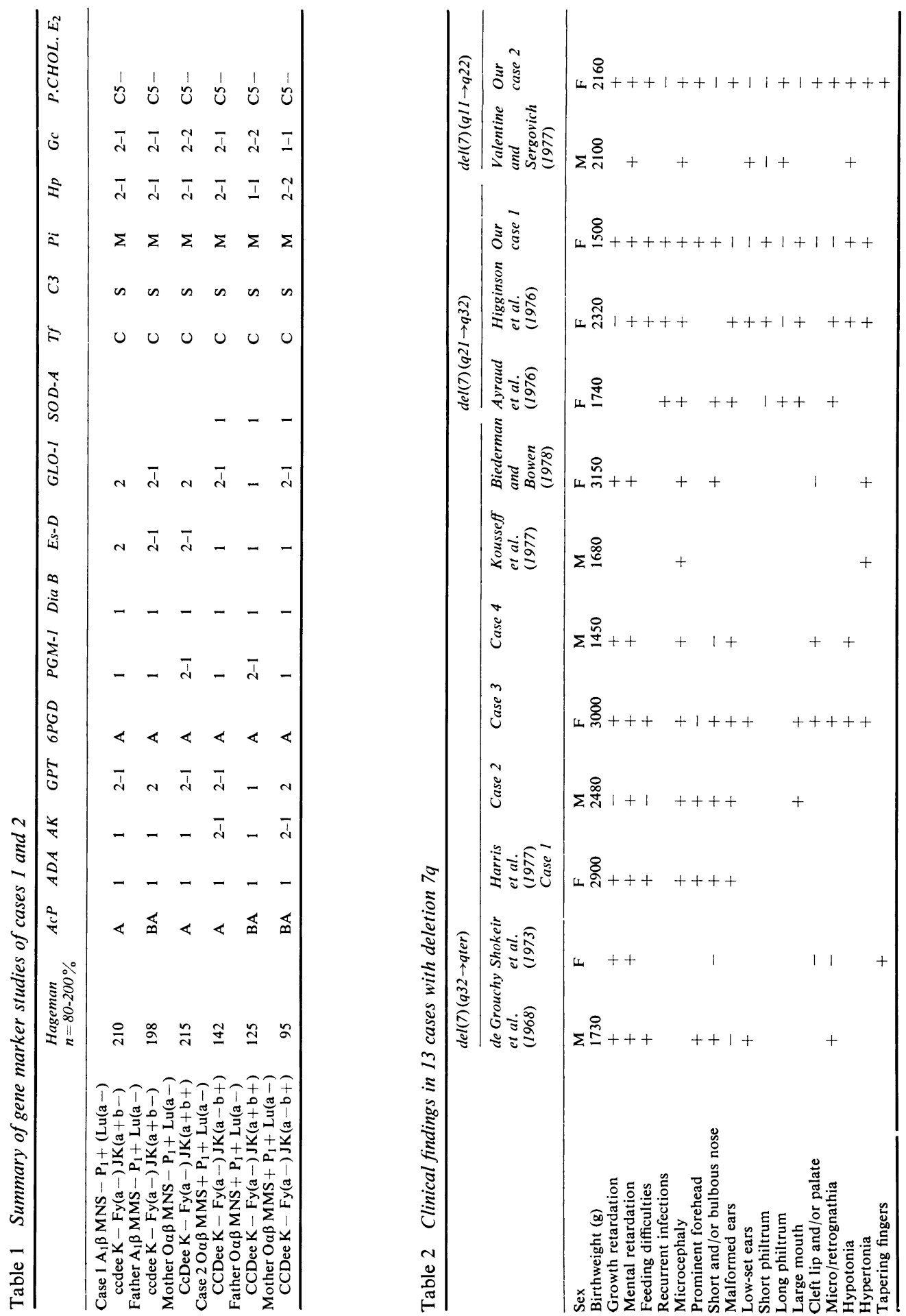
marked micrognathia, thin upper lip, long philtrum, irregularly shaped teeth, small dysplastic ears with prominent antihelices, kyphoscoliosis, a sacral dimple, bilaterally tapering fingers (digits 2 and 5), and general hypotonia with hypertonia of the lower limbs. The patient could not speak and could neither stand nor walk without help. Her hearing was severely impaired. Routine laboratory investigations showed values within normal limits. Dermatoglyphic analysis showed no abnormalities, except for a pattern of abnormal creases overlying the smaller dermal ridges.

\section{Chromosome studies}

Using G-banding (Gallimore and Richardson, 1973) and R-banding (Sehested, 1974), an interstitial deletion of the long arm of a chromosome 7 was found in both cases. The karyotype of case 1 was interpreted as: $46, \mathrm{XX}, \operatorname{del}(7)$ (pter $\rightarrow \mathrm{q} 21:: \mathrm{q} 32 \rightarrow \mathrm{qter})$, and that of case 2 as: $46, X X$,del (7) (pter $\rightarrow$ q11:: q22 $\rightarrow$ qter) (Fig. $2 a$ and b, respectively). The karyotypes of the parents of the two probands were normal.

\section{Gene marker studies}

The Hageman factor, the locus of which has been tentatively assigned to 7q35 (De Grouchy and Turleau, 1974), was within normal limits for both cases, $210 \%$ and $142 \%$ for case 1 and 2 , respectively (normal range 80 to $220 \%$ ). Serum and red cell markers obtained from the patients and their parents revealed no abnormalities. The results are presented in Table 1.

\section{Discussion}

The clinical features of the 13 cases, including our 2 cases, with a deletion 7q are summarised in Table 2 . Since, in these cases at least, 3 different structural aberrations are involved, the patients have been grouped according to the type of the deletion present. The case of Biederman and Bowen (1978) has been grouped arbitrarily under 'terminal deletions', though in their case the Hageman factor was within normal limits. The discrepancy in the case of Biederman and Bowen could be explained by an interstitial deletion in $7 q$ with preservation of the $7 \mathrm{q} 35 \rightarrow$ qter region. In our cases, the Hageman factor was within normal limits, which confirms the findings of De Grouchy and Turleau (1974). Comparison of the clinical data shows no distinct phenotypical differences between the cases in the 3 subgroups. Signs occurring in at least 6 of the 13 patients are: pre- and postnatal growth retardation, mental retardation, feeding difficulties, microcephaly, short and/or bulbous nose, malformed ears, and general hypotonia (in 4 cases combined with hypertonia of the lower limbs). Less frequent: signs are prominent forehead, large mouth, and micro/retrognathia. The above symptoms have been? described in several (partial) trisomy and/or mono somy syndromes. In our opinion, the data presented here neither justify the delineation of a specific $7 q-\bar{\nabla}$ deletion syndrome, nor give evidence for the existence of a pathognomonic sign for such a deletion.

The marker gene typing was partly supported byfunds from the Foundation for Medical Researchw Fungo (grant no. 134114), and was performed by Drs L. E. Nijenhuis, L. F. Bernini, P. Meera Khanọ and J. van Mourik. Ms W. Lodder, M. Melkert and C. E. de France provided technical assistance in the cytogenetic studies.

\section{References}

Ayraud, N., Rovinski, J, Lambert, J. C , and Galiana, AD (1976). Délétion interstitielle du bras long d'un chromo은 some 7 chez une enfant lepréchaune. Annales de Génétique, 19, 265-268.

Biederman, B., and Bowen, P. (1978). Balanced $t(8 ; 9)$ (q12;q33)pat carrier with phenotypic abnormalities attributable to a de novo terminal deletion of the long arm of chromosome 7. Human Genetics, 41, 101-107.

De Grouchy, J., and Turleau, C. (1974). Tentative localization of a Hageman (factor XII) locus on 7q, probably the $7 \mathrm{q} 35$ band. Humangenetik, 24, 197-200.

De Grouchy, J., Veslot, J., Bonnette, J., and Roidot, $\mathbf{M}_{\mathbb{D}}^{\mathbb{D}}$ (1968). A case of ?6p- chromosomal aberration. American Journal of Diseases of Children, 115, 93-99.

Gallimore, P. H., and Richardson, C. R. (1973). An improved banding technique exemplified in the karyotype analysis of two strains of rat. Chromosoma, 41, 259-263.

Harris, E. L., Wappner, R. S., Palmer, C. G., Hall, B. Dinno, N., Seashore, M. R., and Breg, W. R. (1977). 7 $\overline{\mathrm{B}}$ deletion syndrome $(7 \mathrm{q} 32 \rightarrow 7 \mathrm{qter})$. Clinical Genetics, 120 233-238.

Higginson, G., Weaver, D. D., Magenis, R. E., Prescott? G. H., Haag, C., and Hepburn, D. J. (1976). Interstitiaß deletion of the long arm of chromosome no. 7 (7q-) in an infant with multiple anomalies. Clinical Genetics, 10 307-312.

Kousseff, B. G., Hsu, L. Y. F., Paciuc, S., and Hirschhorn, K (1977). A partial long arm deletion of chromosome 70 46,XY,del(7)(q32). Journal of Medical Genetics, 14, 144ㄹ.ᅳ. 147.

Sehested, J. (1974). A simple method for R-banding of human chromosomes showing a pH-dependent connection betweer? R- and G-bands. Humangenetik, 21, 55-58.

Shokeir, M. H. K., Ying, K. L., and Pabello, P. (1973) Deletion of the long arm of chromosome no. 7: tentative assignment of the Kidd (Jk) locus. Clinical Genetics, 40 360-368.

Valentine, H., and Sergovich, F. (1977). A syndrome assoఱ ciated with interstitial deletion of chromosome 7q. Birth Defects: Original Article Series, 14, No. 3B, 261-262.

Requests for reprints to Dr J. B. Bijlsma, Departmen of Human Genetics, University of Amsterdam $\mathbb{\complement}$ Sarphatistraat 217, Amsterdam, The Netherlands. 웅 